\title{
Correlation between Stroke Risk and Systolic Blood Pressure in Patients over 50 Years with Uncontrolled Hypertension: Results from the SYSTUP-India Study
}

\author{
Rishi Sethi ${ }^{1 D},{ }^{1}$ J. S. Hiremath, ${ }^{2}$ V. Ganesh, ${ }^{3}$ Sunip Banerjee, ${ }^{4}$ Mahesh Shah, \\ Ashwani Mehta, ${ }^{6}$ Preeti Nikam, ${ }^{7}$ Minakshi Jaiswal, ${ }^{7}$ and Nishita Shah ${ }^{7}$ \\ ${ }^{1}$ Department of Cardiology, KG's Medical University, Lucknow, India \\ ${ }^{2}$ Cath Lab, Ruby Hall Clinic, Pune, India \\ ${ }^{3}$ Vignesh Heart and Diabetes Centre, Annai Arul Hospital, Chennai, India \\ ${ }^{4}$ S.G. Cardiac Care, Kolkata, India \\ ${ }^{5}$ Nanavati Hospital, Hinduja Hospital, Breach Candy Hospital, Arogyanidhi, BSES MG Hospital, Mumbai, Maharashtra, India \\ ${ }^{6}$ Sir Ganga Ram Hospital, New Delhi, India \\ ${ }^{7}$ Serdia Pharmaceuticals (India) Pvt. Ltd., Mumbai, Maharashtra, India
}

Correspondence should be addressed to Rishi Sethi; drrishisethi1@gmail.com

Received 22 October 2020; Accepted 18 June 2021; Published 29 June 2021

Academic Editor: Victor Garcia

Copyright @ 2021 Rishi Sethi et al. This is an open access article distributed under the Creative Commons Attribution License, which permits unrestricted use, distribution, and reproduction in any medium, provided the original work is properly cited.

\begin{abstract}
Objectives. To assess mean systolic and diastolic blood pressure (SBP and DBP) levels in patients $\geq 50$ years with uncontrolled hypertension (HTN) and evaluate the correlation between BP and stroke risk. It also assessed therapeutic drug classes prescribed in these patients. Methods. A cross-sectional, observational study was conducted at 176 outpatient centers across India, including patients aged $\geq 50$ years with elevated SBP $(\geq 140 \mathrm{mmHg})$. The relationship between stroke risk, calculated using Stroke Riskometer ${ }^{\mathrm{TM}}$, and mean SBP, mean DBP, and other risk factors was evaluated using Pearson correlation coefficient and logistic regression analysis. Results. The study included 3791 patients (men, 60.0\%; mean age: $62.1 \pm 8.3$ years; mean BMI: 27 $\mathrm{kg} / \mathrm{m}^{2}$ ) with mean SBP $157.3 \pm 12.8 \mathrm{mmHg}$ and mean DBP $89.8 \pm 9.7 \mathrm{mmHg}$. Five-year stroke risk in $33.9 \%$ and 10 -year stroke risk in $70 \%$ patients were moderate to severe. A $~ 4 \%$ increase in both 5- and 10-year stroke risk with each $1 \mathrm{mmHg}$ increase in mean SBP $(p<0.0001)$ was seen. However, mean DBP did not exhibit any significant correlation with 5 -year $(p=0.242)$ or 10 year $(p=0.8038)$ stroke risk. There was a positive correlation between mean SBP and patient age, comorbid diabetes, and smoking and alcohol habits $(p<0.0001)$. Comorbid diabetes and smoking increased 5 - and 10 -year stroke risk by 2 - to 5 -fold. Irrespective of the risk category, most patients received antihypertensive therapy with an angiotensin receptor blocker. Conclusion. Findings corroborate an association between stroke risk and mean SBP. These real-world clinical findings indicate that efforts are required to improve primary prevention of stroke and reduce the prevalence of recurrent stroke in India.
\end{abstract}

\section{Introduction}

Hypertension (HTN) is a major risk factor for coronary heart disease and cerebrovascular disease and the leading cardiovascular $(\mathrm{CV})$ risk factor for deaths worldwide $[1,2]$. The global prevalence of HTN, estimated to be 20,526 per 100,000 persons in 2015 , is on a steady rise [3]. The increase in the number of individuals with HTN is associated with a substantial increase in deaths and disability [3]. The number of people with uncontrolled HTN has risen from 594 million in 1975 to nearly 1.13 billion in 2015 [4]. Furthermore, out of the approximately 1.4 billion hypertensive patients globally, only about one in seven achieves adequate blood pressure control [5]. The prevalence of hypertension is reported to be $33.8 \%$ in India, with control rates being as low as $7.9 \%$ $[6,7]$. Moreover, hypertension remains undetected in about $50 \%$ otherwise healthy population, as reported by studies in India and China $[8,9]$. 
Undetected and uncontrolled HTN is a major contributor to stroke worldwide [10]. In India, HTN accounts for $57 \%$ of all stroke deaths and $24 \%$ of all coronary heart disease (CHD) deaths [11]. More than $70 \%$ of all strokes occurring each year are first occurrences, and therefore, the primary prevention of stroke is of immense public health importance [12]. In evidence-based guidelines for the management of risk factors to prevent the first occurrence of stroke, the major focus is on the management of modifiable risk factors, including HTN [13].

Aging induces the progressive stiffening of the large arteries and increases wave reflections with a consequent rise in the systolic blood pressure (SBP) and a decrease in the diastolic blood pressure (DBP) [14]. Increased stiffness and the consequent elevation in blood pressure are associated with an increased risk of stroke [15]. In an aging population, elevated SBP is responsible for most cases of uncontrolled HTN [16]. The increased prevalence of elevated SBP with increasing age has been shown to correlate with an increase in stroke mortality rate [17]. The absolute risk of stroke in a patient with a SBP of $140 \mathrm{mmHg}$ is already three times that of a patient with an optimal SBP of $120 \mathrm{mmHg}$ [17]. Therefore, clinical practice guidelines define normal SBP as $<120$ $\mathrm{mmHg}[18,19]$. Furthermore, it is well established that SBP lowering is effective for the primary prevention of stroke and recurrent stroke prevention $[20,21]$.

Identifying populations or individuals that are at high risk for stroke may aid in optimizing stroke prevention initiatives. An accurate and widely accessible stroke risk prediction tool could help clinicians identify patients at high risk and guide patients to appropriately manage their risk factors in a timely manner. The Stroke Riskometer ${ }^{\mathrm{TM}}$, developed by the National Institute for Stroke and Applied Neurosciences, Auckland University of Technology, uses an algorithm derived from the Framingham Stroke Risk Score (FSRS) prediction algorithm [22] and includes several major risk factors for stroke (both ischemic and hemorrhagic strokes), largely based on the INTERSTROKE study [23]. The application is endorsed by the World Stroke Organization, World Federation of Neurology, and International Association on Neurology and Epidemiology and provides estimates of the absolute risk of stroke within the next 5 to 10 years for individuals aged between 20 and 90 years [24]. The Stroke Riskometer ${ }^{\mathrm{TM}}$ has been successfully validated as being comparable in performance for stroke prediction with the FSRS and QStroke, two widely used stroke risk scoring systems [24].

Renin-angiotensin receptor inhibitors, calcium channel blockers (CCBs), and diuretics (particularly thiazide-like diuretics) are the commonly recommended classes of antihypertensive medications $[18,19,25]$. The selection of appropriate antihypertensive agents for patients is crucial for hypertension management. Moreover, measures to improve adherence, such as the use of fixed-dose combination drugs, also increase the BP control rate and reduce the risk of stroke $[13,26]$.

The SYSTolic blood pressUre in older Patients with hypertension (SYSTUP), in relation to stroke risk and current antihypertensive treatment strategies, was a cross-sectional, observational study designed to assess mean SBP in patients with uncontrolled HTN and evaluate the correlation between blood pressure and stroke risk in a real-world clinical setting in India. Further, information on different classes of antihypertensive drugs prescribed to hypertensive patients was collected.

\section{Materials and Methods}

2.1. Study Design and Data Collection. The SYSTUP study was a single-visit, prospective, noninterventional, observational study conducted at 176 outpatient centers across India. Over a period of 4 weeks, participating physicians each recruited 25 consecutive patients who met the inclusion criteria. Demographic and clinical data, including age, sex, ethnicity, BMI, blood pressure, diabetes, smoking and alcohol habits, family history of and prior CV disease, and physical activity (at least 2.5 hours per week), were collected during the study visit using a structured form. Five-year and 10year stroke risk score was obtained for each patient using the Stroke Riskometer ${ }^{\mathrm{TM}}$ application, which could be downloaded from Google Play (for Android) or App Store (for Apple) [27]. Patients were categorized into four risk categories based on their stroke risk score: low risk, $<0.1$; moderate risk, $0.1-<0.2$; high risk, $0.2-<0.3$; and very high risk, $\geq 0.3$. The study was approved by local institutional review boards, and all patients provided informed consent in accordance with national and international guidelines.

2.2. Patients. This study included hypertensive patients who presented at the outpatient clinic for a routine consultation. The key inclusion criteria were at least 50 years of age with a confirmed diagnosis of hypertension and elevated SBP, defined as $\geq 140 \mathrm{mmHg}$, during the study visit. Blood pressure was measured according to the European Society of Hypertension (ESH) guidelines using an auscultatory or oscillometric semiautomatic sphygmomanometer [28]. Patients remained seated for 3-5 minutes before the BP was measured. The higher of at least two measurements taken 1-2 minutes apart was documented. Patients with any condition that could prevent participation, such as inability to complete the consent form, were excluded.

2.3. Statistical Analysis. Categorical parameters were presented using descriptive statistics, and continuous variables were presented as mean $\pm \mathrm{SD}$. The relationship between mean SBP/mean DBP and stroke risk was evaluated using the Pearson correlation coefficient. Logistic regression analysis was used to assess the relationship between 5-year and 10year risk and risk factors, including age, presence of diabetes, physical activity, and smoking and alcohol habits. All analyses were performed using SAS software (version 9.4).

\section{Results}

3.1. Patient Characteristics. The analysis included 3791 patients (men, 60.0\%). The mean age was $62.1 \pm 8.3$ years, and the mean BMI is $27.0 \pm 8.3 \mathrm{~kg} / \mathrm{m}^{2}$ (Table 1). Majority of the patients were less than 70 years old (79.4\%) and overweight or obese $(80.4 \%)$, smoked $(32.2 \%)$, and consumed alcohol (21.6\%). Approximately $50 \%$ of the patients engaged 
TABLE 1: Demographic and clinical characteristics of patients.

\begin{tabular}{lc}
\hline Characteristic & $N=3791$ \\
\hline Mean age \pm SD (years) & $62.1 \pm 8.3$ \\
Male & $2275(60.0)$ \\
Indian ethnicity & $3746(98.8)$ \\
Mean BMI \pm SD $\left(\mathrm{kg} / \mathrm{m}^{2}\right)$ & $27.0 \pm 8.3$ \\
BMI categories & \\
$\quad$ Underweight & $55(1.5)$ \\
$\quad$ Normal & $688(18.1)$ \\
$\quad$ Overweight & $657(17.3)$ \\
$\quad$ Obese & $2391(63.1)$ \\
Smoker & $1220(32.2)$ \\
Consumed alcohol $>1$ standard drink per day) & $819(21.6)$ \\
Consumed enough fruits/vegetables & $1990(52.5)$ \\
Physical activity (for at least 2.5 hours per week) & $1941(51.2)$ \\
Mental/emotional stress & $1345(35.5)$ \\
Family history of stroke/heart attack < 65y & $918(24.2)$ \\
Diabetes & $1922(50.7)$ \\
Peripheral artery disease & $847(22.3)$ \\
Left ventricular hypertrophy & $572(15.1)$ \\
Atrial fibrillation & $281(7.4)$ \\
Cognitive problem & $342(9.0)$ \\
Poor memory & $727(19.2)$ \\
Brain injury & $89(2.3)$ \\
Previous stroke or TIA & $313(8.3)$ \\
Mean SBP & $157.3 \pm 12.8$ \\
Mean DBP & $2304(60.8 \pm 9.7$ \\
Antihypertensive treatment & $3791(100)$ \\
\hline Vase combination therapy & $1026(27.1)$ \\
\hline
\end{tabular}

Values represent $n$ (\%) unless specified otherwise. BMI: body mass index; TIA: transient ischemic attack.

in regular physical activity. Majority of the patients did not have vascular complications, although diabetes, a known $\mathrm{CV}$ risk factor, was present in $\sim 50 \%$ of the patients.

3.2. Mean Blood Pressure Level and Its Correlation with Age and Stroke Risk. Mean SBP and DBP were 157.3 \pm 12.8 $\mathrm{mmHg}$ and $89.8 \pm 9.7 \mathrm{mmHg}$, respectively (Table 1 ). There was a positive correlation between mean SBP and patient age $\left(r^{2}, 0.172 ; p<0.0001\right)$; mean SBP was higher in older age groups (Table 2). The greatest reduction in stroke risk could be obtained by lowering the $\mathrm{BP}$ in the age group $\leq 79$ years.

Majority of the patients had a low 5-year stroke risk $(66.1 \%)$. However, the proportion of patients with low 10year stroke risk was $30 \%$, while the remaining $70 \%$ of patients had moderate to very high risk. A significant positive correlation was found between mean SBP and 5-year (likelihood estimate, $0.038 ; p<0.0001$ ) and 10-year stroke risk (likelihood estimate, $0.036 ; p<0.0001$ ) (Table 2). There was an approximate $4 \%$ increase in both 5 -year and 10 -year stroke
TABLE 2: Correlation between mean systolic BP and age, 5-year stroke risk, and 10-year stroke risk.

\begin{tabular}{lrccc}
\hline & $n$ & MSBP & Correlation & $p$ value \\
\hline Age & & & & \\
$\quad 50-59$ years & 1623 & $155.61 \pm 12.45$ & & \\
$\quad 60-69$ years & 1387 & $157.13 \pm 12.00$ & & \\
$70-79$ years & 634 & $159.99 \pm 14.13$ & $0.172^{\mathrm{a}}$ & $<0.0001$ \\
$>80$ years & 147 & $164.86 \pm 14.39$ & & \\
5-year stroke risk & & & & \\
$\quad$ Low $(<0.1)$ & 2504 & $155.12 \pm 11.69$ & & \\
$\quad$ Moderate $(0.1-$ & 769 & $160.41 \pm 14.20$ & -6.72 & $<0.0001$ \\
$<0.2)$ & 255 & $161.75 \pm 13.75$ & $(0.44)^{\mathrm{b}}$ & \\
$\quad$ High $(0.2-<0.3)$ & & & \\
$\quad$ Very high $(\geq 0.3)$ & 263 & $164.07 \pm 12.93$ & & \\
10 -year stroke risk & & & & \\
$\quad$ Low $(<0.1)$ & 1119 & $153.50 \pm 11.36$ & & \\
$\quad$ Moderate $(0.1-$ & 1176 & $155.88 \pm 11.68$ & -4.76 & $<0.0001$ \\
$<0.2)$ & & & & \\
$\quad$ High $(0.2-<0.3)$ & 583 & $160.36 \pm 13.29$ & $(0.50)^{\mathrm{b}}$ & \\
$\quad$ Very high $(\geq 0.3)$ & 913 & $161.66 \pm 13.92$ & & \\
\hline
\end{tabular}

${ }^{a}$ Data represent Pearson correlation coefficient $\left(r^{2}\right)$. ${ }^{b}$ Data represent maximum likelihood estimate for intercept (standard error).

risk with every $1 \mathrm{mmHg}$ increase in mean SBP. On the other hand, mean DBP did not exhibit any significant correlation with either 5 -year $\left(r^{2}, 0.019 ; p=0.242\right)$ or 10 -year stroke risk $\left(r^{2}, 0.004 ; p=0.8038\right)$ (Table 3$)$.

3.3. Correlation between Stroke Risk and Other Risk Factors. Among the risk factors assessed, increasing age, presence of diabetes, smoking, and alcohol consumption ( $>1$ standard drink per day) were all significantly correlated with an increased stroke risk ( $p<0.0001$ for all), while regular physical activity had a significant negative association with stroke risk $(p<0.0001)$ (Table 3). Five-year stroke risk was $\sim 2$-fold higher among diabetic patients than those without diabetes (odds ratio (OR), 1.94) and among smokers than nonsmokers (OR, 2.09). Smoking had the strongest impact on 10-year stroke risk (OR, 5.714), followed by alcohol consumption (OR, 3.274) and the presence of diabetes (OR, 2.516).

3.4. Stroke Risk and Antihypertensive Medication. All patients were receiving antihypertensive therapy. Nearly one-third of the patients $(1026 / 3791)$ were using a fixed-dose combination (Table 1 ), and $\sim 15 \%(575 / 3791)$ of the patients were receiving three or more classes of antihypertensive drugs (Figure 1). Commonly prescribed antihypertensive drugs were ARBs (39.2\%), CCBs (33.7\%), and diuretics (28.4\%), while alpha blockers and centrally acting agents were rarely prescribed in these patients (1.4\%). The proportion of patients using different classes of antihypertensive drugs did not differ across stroke-risk categories (Table 4). 
TABLE 3: Correlation between CV risk factors and stroke risk.

\begin{tabular}{|c|c|c|c|c|c|c|c|c|c|c|c|}
\hline & \multirow[b]{2}{*}{$N$} & \multicolumn{5}{|c|}{ 5-year stroke risk } & \multicolumn{5}{|c|}{10 -year stroke risk } \\
\hline & & Low & Moderate & High & $\begin{array}{l}\text { Very } \\
\text { high }\end{array}$ & $\mathrm{OR} / r^{2}$ & Low & Moderate & High & $\begin{array}{l}\text { Very } \\
\text { high }\end{array}$ & $\mathrm{OR} / r^{2}$ \\
\hline Total & 3791 & $\begin{array}{c}2504 \\
(66.1)\end{array}$ & $\begin{array}{c}769 \\
(20.3)\end{array}$ & $\begin{array}{l}255 \\
(6.7)\end{array}$ & $\begin{array}{l}263 \\
(6.9)\end{array}$ & - & $\begin{array}{c}1119 \\
(29.5)\end{array}$ & $\begin{array}{c}1176 \\
(31.0)\end{array}$ & $\begin{array}{c}583 \\
(15.4)\end{array}$ & $\begin{array}{c}913 \\
(24.1)\end{array}$ & - \\
\hline \multicolumn{12}{|l|}{ Age } \\
\hline $\begin{array}{l}50-59 \\
\text { years }\end{array}$ & 1623 & $\begin{array}{c}1315 \\
(34.7)\end{array}$ & $231(6.1)$ & $49(1.3)$ & $28(0.7)$ & & $\begin{array}{c}840 \\
(22.2)\end{array}$ & $\begin{array}{c}433 \\
(11.4)\end{array}$ & $\begin{array}{c}170 \\
(4.5)\end{array}$ & $\begin{array}{l}180 \\
(4.7)\end{array}$ & \multirow{4}{*}{$-/ 0.453^{* *}$} \\
\hline $\begin{array}{l}\text { 60-69 } \\
\text { years }\end{array}$ & 1387 & $\begin{array}{c}892 \\
(23.5)\end{array}$ & $280(7.4)$ & $\begin{array}{l}116 \\
(3.1)\end{array}$ & $99(2.6)$ & \multirow[t]{3}{*}{$-/ 0.415^{* *}$} & $248(6.5)$ & $\begin{array}{c}557 \\
(14.7)\end{array}$ & $\begin{array}{l}219 \\
(5.8)\end{array}$ & $\begin{array}{l}363 \\
(9.6)\end{array}$ & \\
\hline $\begin{array}{l}70-79 \\
\text { years }\end{array}$ & 634 & $268(7.1)$ & $197(5.2)$ & $76(2.0)$ & $93(2.5)$ & & $27(0.7)$ & $173(4.6)$ & $\begin{array}{c}154 \\
(4.1)\end{array}$ & $\begin{array}{l}280 \\
(7.4)\end{array}$ & \\
\hline$>80$ years & 147 & $29(0.8)$ & $61(1.17)$ & $14(0.4)$ & $43(1.2)$ & & $4(0.1)$ & $13(0.3)$ & $40(1)$ & $90(2.4)$ & \\
\hline \multicolumn{12}{|l|}{ BMI category } \\
\hline Underweight & 55 & $36(0.9)$ & $11(0.3)$ & $2(0.1)$ & $6(0.2)$ & \multirow{4}{*}{$-/-0.030$} & $14(0.4)$ & $17(0.4)$ & $8(0.2)$ & $16(0.4)$ & \multirow{4}{*}{$-/-0.038^{*}$} \\
\hline Normal & 688 & $\begin{array}{c}430 \\
(11.3)\end{array}$ & $150(4.0)$ & $45(1.2)$ & $63(1.7)$ & & $192(5.1)$ & $200(5.3)$ & $\begin{array}{c}107 \\
(2.8)\end{array}$ & $\begin{array}{c}189 \\
(5.0)\end{array}$ & \\
\hline Overweight & 657 & $\begin{array}{c}458 \\
(12.1)\end{array}$ & $124(3.3)$ & $42(1.1)$ & $33(0.9)$ & & $187(4.9)$ & $238(6.3)$ & $95(2.5)$ & $\begin{array}{c}137 \\
(3.6)\end{array}$ & \\
\hline Obese & 2391 & $\begin{array}{c}1580 \\
(41.7)\end{array}$ & $\begin{array}{c}484 \\
(12.8)\end{array}$ & $\begin{array}{c}166 \\
(4.4)\end{array}$ & $\begin{array}{c}161 \\
(4.2)\end{array}$ & & $\begin{array}{c}726 \\
(19.2)\end{array}$ & $\begin{array}{c}721 \\
(19.0)\end{array}$ & $\begin{array}{c}373 \\
(9.8)\end{array}$ & $\begin{array}{c}571 \\
(15.1)\end{array}$ & \\
\hline \multicolumn{12}{|l|}{ Diastolic $\mathrm{BP}^{\mathrm{a}}$} \\
\hline Uncontrolled & 2304 & $\begin{array}{c}1487 \\
(39.2)\end{array}$ & $\begin{array}{c}494 \\
(13.0)\end{array}$ & $\begin{array}{c}158 \\
(4.2)\end{array}$ & $\begin{array}{c}165 \\
(4.4)\end{array}$ & \multirow{2}{*}{$-/ 0.019$} & $\begin{array}{c}626 \\
(16.5)\end{array}$ & $\begin{array}{c}729 \\
(19.2)\end{array}$ & $\begin{array}{c}371 \\
(9.8)\end{array}$ & $\begin{array}{c}578 \\
(15.2)\end{array}$ & \multirow{2}{*}{$-/ 0.004$} \\
\hline Controlled & 1487 & $\begin{array}{c}1017 \\
(26.8)\end{array}$ & $275(7.3)$ & $97(2.6)$ & $98(2.6)$ & & $493(13)$ & $\begin{array}{c}447 \\
(11.8)\end{array}$ & $\begin{array}{l}212 \\
(5.6)\end{array}$ & $\begin{array}{c}335 \\
(8.8)\end{array}$ & \\
\hline \multicolumn{12}{|l|}{ Diabetes } \\
\hline Yes & 1922 & $\begin{array}{c}1130 \\
(29.8)\end{array}$ & $\begin{array}{c}442 \\
(11.7)\end{array}$ & $\begin{array}{c}160 \\
(4.2)\end{array}$ & $\begin{array}{c}190 \\
(5.0)\end{array}$ & \multirow{2}{*}{$1.943 / 0.665^{* *}$} & $\begin{array}{c}392 \\
(10.3)\end{array}$ & $\begin{array}{c}616 \\
(16.2)\end{array}$ & $\begin{array}{c}321 \\
(8.5)\end{array}$ & $\begin{array}{c}593 \\
(15.6)\end{array}$ & \multirow{2}{*}{$2.516 / 0.923^{* *}$} \\
\hline No & 1869 & $\begin{array}{c}1374 \\
(36.2)\end{array}$ & $327(8.6)$ & $95(2.5)$ & $73(1.9)$ & & $\begin{array}{c}727 \\
(19.2)\end{array}$ & $\begin{array}{c}560 \\
(14.8)\end{array}$ & $\begin{array}{c}262 \\
(6.9)\end{array}$ & $\begin{array}{c}320 \\
(8.4)\end{array}$ & \\
\hline \multicolumn{12}{|c|}{ Physical activity } \\
\hline Yes & 1941 & $\begin{array}{c}1340 \\
(35.3)\end{array}$ & $354(9.3)$ & $\begin{array}{c}122 \\
(3.2)\end{array}$ & $\begin{array}{c}125 \\
(3.3)\end{array}$ & \multirow{2}{*}{$0.759 /-0.276^{* *}$} & $\begin{array}{c}613 \\
(16.2)\end{array}$ & $\begin{array}{c}624 \\
(16.5)\end{array}$ & $\begin{array}{c}264 \\
(7.0)\end{array}$ & $\begin{array}{c}440 \\
(11.6)\end{array}$ & \multirow{2}{*}{$0.829 / 0.187^{* *}$} \\
\hline No & 1850 & $\begin{array}{c}1164 \\
(30.7)\end{array}$ & $\begin{array}{c}415 \\
(10.9)\end{array}$ & $\begin{array}{l}133 \\
(3.5)\end{array}$ & $\begin{array}{l}138 \\
(3.6)\end{array}$ & & $\begin{array}{c}506 \\
(13.3)\end{array}$ & $\begin{array}{c}552 \\
(14.6)\end{array}$ & $\begin{array}{l}319 \\
(8.4)\end{array}$ & $\begin{array}{c}473 \\
(12.5)\end{array}$ & \\
\hline \multicolumn{12}{|l|}{ Smoker } \\
\hline Yes & 1220 & $\begin{array}{c}666 \\
(17.6)\end{array}$ & $306(8.1)$ & $\begin{array}{c}115 \\
(3.0)\end{array}$ & $\begin{array}{l}133 \\
(3.5)\end{array}$ & \multirow{2}{*}{$2.09 / 0.739^{* *}$} & $122(3.2)$ & $\begin{array}{c}449 \\
(11.8)\end{array}$ & $\begin{array}{c}226 \\
(6.0)\end{array}$ & $\begin{array}{c}423 \\
(11.2)\end{array}$ & \multirow{2}{*}{$5.714 / 1.743^{* *}$} \\
\hline No & 2571 & $\begin{array}{c}1838 \\
(48.5)\end{array}$ & $\begin{array}{c}463 \\
(12.2)\end{array}$ & $\begin{array}{c}140 \\
(3.7)\end{array}$ & $\begin{array}{c}130 \\
(3.4)\end{array}$ & & $\begin{array}{c}997 \\
(26.3)\end{array}$ & $\begin{array}{c}727 \\
(19.2)\end{array}$ & $\begin{array}{l}357 \\
(9.4)\end{array}$ & $\begin{array}{c}490 \\
(12.9)\end{array}$ & \\
\hline \multicolumn{12}{|l|}{ Alcohol } \\
\hline Yes & 819 & $\begin{array}{c}459 \\
(12.1)\end{array}$ & $191(5.0)$ & $84(2.2)$ & $85(2.2)$ & \multirow{2}{*}{$1.733 / 0.550^{* *}$} & $112(3.0)$ & $278(7.3)$ & $\begin{array}{c}154 \\
(4.1)\end{array}$ & $\begin{array}{c}275 \\
(7.3)\end{array}$ & \multirow{2}{*}{$3.274 / 1.186^{* *}$} \\
\hline No & 2972 & $\begin{array}{c}2045 \\
(53.9)\end{array}$ & $\begin{array}{c}578 \\
(15.2)\end{array}$ & $\begin{array}{c}171 \\
(4.5)\end{array}$ & $\begin{array}{c}178 \\
(4.7)\end{array}$ & & $\begin{array}{c}1007 \\
(26.6)\end{array}$ & $\begin{array}{c}898 \\
(23.7)\end{array}$ & $\begin{array}{c}429 \\
(11.3)\end{array}$ & $\begin{array}{c}638 \\
(16.8)\end{array}$ & \\
\hline
\end{tabular}

\section{Discussion}

In this observational study, SBP was found to have a significant impact on both 5-year and 10-year stroke risk in patients over 50 years of age with uncontrolled HTN. Fiveyear stroke risk was moderate to severe in one-third of the patients, whereas the corresponding proportion of patients for 10 -year stroke risk was $70 \%$.

There was a significant positive correlation between age and mean SBP $(p<0.0001)$. These results are in line with observations from other epidemiological studies, which have shown that while DBP increases until the sixth decade of life 


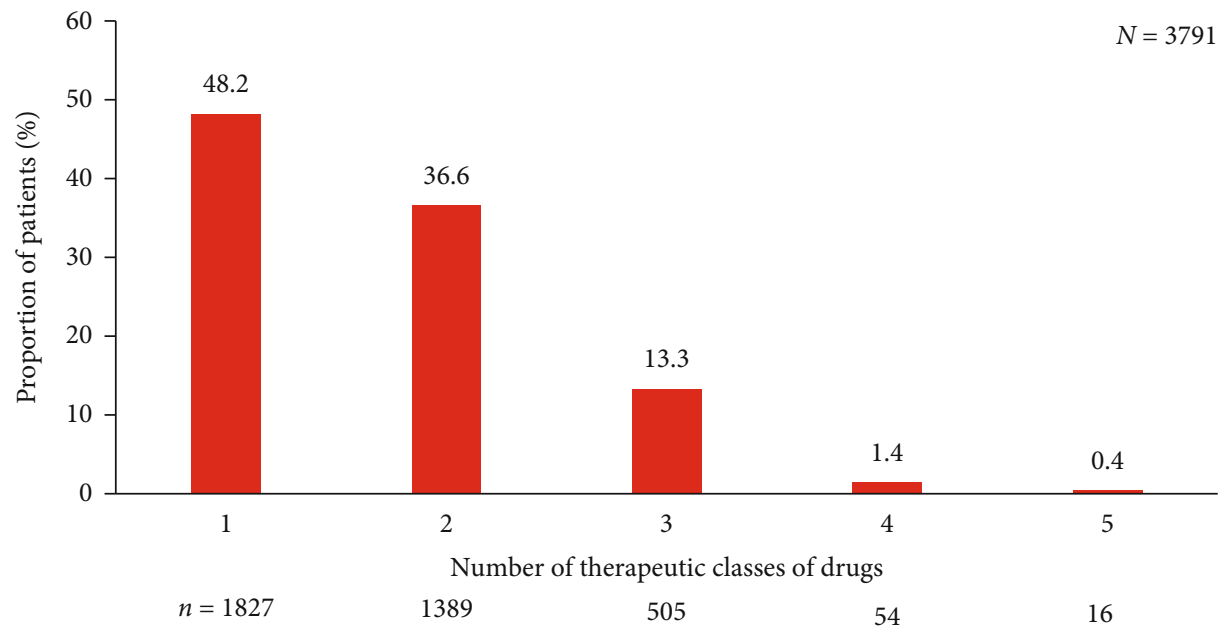

FIGURE 1: Proportion of patients using one or more classes of antihypertensive drugs.

TABLE 4: Therapeutic class of drugs stratified by risk of stroke.

\begin{tabular}{|c|c|c|c|c|c|c|c|c|c|}
\hline \multirow{2}{*}{ Therapeutic class } & \multirow[b]{2}{*}{ Total } & \multicolumn{4}{|c|}{5 -year stroke risk $(N=3791)$} & \multicolumn{4}{|c|}{10 -year stroke risk $(N=3791)$} \\
\hline & & Low & Moderate & High & Very high & Low & Moderate & High & Very high \\
\hline$N$ & 3791 & 2504 & 769 & 255 & 263 & 1119 & 1176 & 583 & 913 \\
\hline ACE inhibitor & $658(17.4)$ & $424(16.9)$ & $118(15.3)$ & $62(24.3)$ & $54(20.5)$ & $154(13.8)$ & $224(19.0)$ & $99(17.0)$ & $181(19.8)$ \\
\hline Angiotensin receptor blocker & $1487(39.2)$ & $916(36.6)$ & $337(43.8)$ & $123(48.2)$ & $111(42.2)$ & $412(36.8)$ & $427(36.3)$ & $242(41.5)$ & $406(44.5)$ \\
\hline Beta blocker & $840(22.2)$ & $507(20.2)$ & $198(25.7)$ & $59(23.1)$ & $76(28.9)$ & $212(18.9)$ & $239(20.3)$ & $144(24.7)$ & $245(26.8)$ \\
\hline Calcium channel blocker & $1276(33.7)$ & $845(33.7)$ & $256(33.3)$ & $87(34.1)$ & $88(33.5)$ & $371(33.2)$ & $402(34.2)$ & $207(35.5)$ & $296(32.4)$ \\
\hline Diuretic & $1077(28.4)$ & $643(25.7)$ & $241(31.3)$ & $98(38.4)$ & $95(36.1)$ & $275(24.6)$ & $320(27.2)$ & $159(27.3)$ & $323(35.4)$ \\
\hline Alpha blocker or CAA & $52(1.4)$ & $28(1.1)$ & $14(1.8)$ & $4(1.6)$ & $6(2.3)$ & $11(1.0)$ & $15(1.3)$ & $9(1.5)$ & $17(1.9)$ \\
\hline
\end{tabular}

Values represent $n$ (\%). $N$ represents the total number of patients and the denominator for calculating the percentages in each column. The total of percentages in any column is higher than 100 as some patients were receiving more than one antihypertensive drug and hence included each drug class. ACE: angiotensinconverting enzyme; CAA: centrally acting agent.

and decreases thereafter, SBP continues to increase with age $[29,30]$. Higher SBP in older age is correlated with an increased CV and cerebrovascular disease risk [29, 30]. Further, it is known that age and HTN are key risk factors for stroke. Hence, we sought to investigate stroke risk among older hypertensive patients.

In addition to age and elevated SBP, lifestyle factors such as obesity, lack of exercise, smoking, alcohol, and stress have been associated with an increased risk of stroke [31]. The relative incidence of stroke compared with myocardial infarction is reported to be significantly higher in women $\geq 65$ years and in men $>75$ years than younger women and men [32]. This highlights the importance of stroke prevention in patients above the age of 65 years. Lifestyle modifications including weight reduction, low-risk diet, regular physical activity, smoking cessation, and low-to-moderate alcohol consumption may reduce stroke risk by up to $50 \%$ [33]. In the present study, risk factors such as increasing age, presence of diabetes, smoking, and alcohol consumption were all associated with higher stroke risk, while regular physical activity was associated with lower stroke risk. These results are in line with previous reports and corroborate the need to actively manage lifestyle factors in older hypertensive patients [30].
Five-year stroke risk was generally low; however, 10year stroke risk was moderate to very high in a majority of the patients. There were significant positive correlations between mean SBP and 5-year and 10-year stroke risk $(p<0.0001)$. These results underscore the importance of reducing blood pressure in older patients for stroke prevention. It must be noted that all patients included in this analysis were receiving antihypertensive drugs, and 51.7\% of the patients were using a combination of two or more classes of antihypertensive drugs (Figure 1). A similar pattern of antihypertensive use was also observed in an international i-SEARCH registry: approximately $31.2 \%$ of the patients were receiving $1 ; 39.7 \%, 2$; and $29.1 \%, \geq 3$ drugs [34]. Even though more than half of the patients were treated with combination therapy, the $\mathrm{BP}$ control rates were poor in our study $(39.2 \%)$ and the i-SEARCH registry $(21.2 \%)$. Low blood pressure control rate could be attributed to inappropriate selection of antihypertensive agents or low adherence to prescribed medications. The most commonly prescribed blood pressure-lowering agents were ARBs followed by CCBs and diuretics, irrespective of stroke risk. Systematic reviews and meta-analyses of trials involving $\mathrm{ARBs}$ have shown that $\mathrm{ARBs}$ are inferior to 
angiotensin-converting enzyme (ACE) inhibitors in preventing myocardial infarction and mortality [35]. Moreover, in the 2012 Kidney Disease: Improving Global Outcomes (KDIGO) guideline, ACE inhibitors are stated as the commonly recommended antihypertensive drugs in comorbid hypertension and renal impairment; ARBs are recommended when ACE inhibitors are not tolerated or contraindicated [36]. Moreover, the latest ESC-EASD 2019 guidelines also recommend ACE inhibitors as first-line antihypertensive, and ARBs are recommended only in ACE-intolerant patients [25].

Increasing adherence to treatment has been shown to improve blood control rates and reduce the stroke risk by about one-third [13]. However, majority of hypertension guidelines acknowledge that improving adherence to antihypertensive treatment remains a major challenge for clinical practice in the future $[18,19]$. Fixed-dose single-pill combinations (SPCs) have been shown to increase compliance by approximately $26 \%$ [26]. In this regard, fixed-dose combinations of perindopril/indapamide and perindopril/indapamide/amlodipine are the only SPCs that are based on ACE inhibitors. The treatment with fixed-dose combinations of perindopril and indapamide and amlodipine has been demonstrated to improve the BP control in several randomized trials and real-world studies [37, 38]. The decrease in BP was associated with a reduction in the risk of nonfatal myocardial infarction, all-cause mortality, total cardiovascular events and procedures, and cardiovascular mortality [39, 40]. Therefore, the use of fixed-dose SPCs could provide a tool to improve the medication adherence and BP control rate in the routine clinical practice in India.

The main limitations of our study were as follows: crosssectional design; no assessment of adherence to medications, duration of hypertension, gender effect, fatal or nonfatal stroke; and the lack of a detailed analysis of resistant HTN and stroke risk among patients with resistant HTN. However, the key strength of our study is the collection of realworld data across India.

\section{Conclusion}

Overall, in a real-world clinical setting in India, SBP was found to have a significant impact on both 5-year and 10year stroke risk in patients over 50 years of age with uncontrolled HTN. Majority of the patients were at moderate to very high 10-year stroke risk. In addition to age and elevated SBP, factors such as the presence of diabetes, lack of regular physical activity, and smoking and alcohol habits were all associated with an increased stroke risk. ARBs were the most commonly prescribed antihypertensive agents for older hypertensive patients in clinical practice in India. These findings support the strengthening of primary care to improve primary prevention and reduce the occurrence of stroke.

\section{Data Availability}

The datasets used and analyzed during the current study are available from the corresponding author on reasonable request.

\section{Disclosure}

The abstract was presented as an oral presentation titled "Epidemiological Study Evaluating Uncontrolled Systolic Blood Pressure In Patients $\geq 50$ Years With Hypertension, In Relation To Stroke Risk And Current Antihypertensive Treatment Strategies (SYSTUP)-Analysis Of India Cohort" at the Joint Hypertension 2018 Scientific Sessions, a collaborative effort with the American Heart Association's Council on Hypertension, Council on the Kidney in Cardiovascular Disease, and the American Society of Hypertension.

\section{Conflicts of Interest}

Dr. Preeti Nikam, Dr. Minakshi Jaiswal, and Dr. Nishita Shah are employees of Serdia Pharmaceuticals (India) Pvt. Ltd. All other authors have no conflicts of interest.

\section{Acknowledgments}

The authors would like to thank CBCC Global Research for providing medical writing assistance. The study was sponsored by Serdia Pharmaceuticals (India) Pvt. Ltd.

\section{References}

[1] World Health Organization, Prevention of Cardiovascular Disease: Guidelines for Assessment and Management of Cardiovascular Risk, World Health Organization, Geneva, Switzerland, 2007.

[2] S. Mendis, P. Puska, and B. Norrving, Global Atlas on Cardiovascular Disease Prevention and Control, World Health Organization, Geneva, Switzerland, 2011.

[3] M. H. Forouzanfar, P. Liu, G. A. Roth et al., "Global burden of hypertension and systolic blood pressure of at least 110 to 115 mm Hg, 1990-2015," JAMA, vol. 317, no. 2, pp. 165-182, 2017.

[4] WHO Fact sheet, "Hypertension," September 2019, https:// www.who.int/news-room/fact-sheets/detail/hypertension.

[5] K. T. Mills, J. D. Bundy, T. N. Kelly et al., "Global disparities of hypertension prevalence and Control," Circulation, vol. 134, no. 6, pp. 441-450, 2016.

[6] R. Gupta, K. Gaur, and C. V. S. Ram, "Emerging trends in hypertension epidemiology in India," Journal of Human Hypertension, vol. 33, no. 8, pp. 575-587, 2019.

[7] J. Prenissl, J. Manne-Goehler, L. M. Jaacks et al., "Hypertension screening, awareness, treatment, and control in India: a nationally representative cross-sectional study among individuals aged 15 to 49 years," PLoS medicine, vol. 16, no. 5, 2019.

[8] A. N. Shukla, T. Madan, B. M. Thakkar, M. M. Parmar, and K. H. Shah, "Prevalence and predictors of undiagnosed hypertension in an apparently healthy western Indian population," Advances in Epidemiology, vol. 2015, Article ID 649184, 5 pages, 2015.

[9] T. S. Han, H. H. Wang, L. Wei et al., "Impacts of undetected and inadequately treated hypertension on incident stroke in China," BMJ Open, vol. 7, no. 10, 2017.

[10] A. Alwan, Global Status Report on Noncommunicable Diseases 2010, World Health Organization, Geneva, Switzerland, 2010.

[11] R. Gupta, "Trends in hypertension epidemiology in India," Journal of Human Hypertension, vol. 18, no. 2, pp. 73-78, 2004. 
[12] American Heart Association, Heart disease and stroke statistics-2004 update, American Heart Association, Dallas, TX, USA, 2003.

[13] J. F. Meschia, C. Bushnell, B. Boden-Albala et al., "Guidelines for the primary prevention of stroke," Stroke, vol. 45, no. 12, pp. 3754-3832, 2014.

[14] S. Pagoulatou and N. Stergiopulos, "Evolution of aortic pressure during normal ageing: a model-based study," PLoS One, vol. 12, no. 7, 2017.

[15] S. Laurent, S. Katsahian, C. Fassot et al., "Aortic stiffness is an independent predictor of fatal stroke in essential hypertension," Stroke, vol. 34, no. 5, pp. 1203-1206, 2003.

[16] G. Mancia and G. Grassi, "Systolic and diastolic blood pressure control in antihypertensive drug trials," Journal of Hypertension, vol. 20, no. 8, pp. 1461-1464, 2002.

[17] S. Lewington, R. Clarke, N. Qizilbash, R. Peto, R. Collins, and Prospective Studies Collaboration, "Age-specific relevance of usual blood pressure to vascular mortality: a meta- analysis of individual data for one million adults in 61 prospective studies," Lancet, vol. 360, no. 9349, pp. 1903-1913, 2002.

[18] P. K. Whelton, R. M. Carey, W. S. Aronow et al., "2017 ACC/AHA/AAPA/ABC/ACPM/AGS/APhA/ASH/ASPC/NMA/PCNA guideline for the prevention, detection, evaluation, and management of high blood pressure in adults: a report of the American College of Cardiology/American Heart Association Task Force on Clinical Practice Guidelines," Hypertension, vol. 71, no. 6, pp. e13-e115, 2018.

[19] B. Williams, G. Mancia, W. Spiering et al., "2018 ESC/ESH guidelines for the management of arterial hypertension," European Heart Journal, vol. 39, no. 33, pp. 3021-3104, 2018.

[20] R. S. Vasan, A. Beiser, S. Seshadri et al., "Residual lifetime risk for developing hypertension in middle-aged women and men: the Framingham Heart Study," JAMA, vol. 287, no. 8, pp. 1003-1010, 2002.

[21] B. Ovbiagele, H. C. Diener, S. Yusuf et al., "Level of systolic blood pressure within the normal range and risk of recurrent stroke," JAMA, vol. 306, no. 19, pp. 2137-2144, 2011.

[22] P. A. Wolf, R. B. D'Agostino, A. J. Belanger, and W. B. Kannel, "Probability of stroke: a risk profile from the Framingham study," Stroke, vol. 22, no. 3, pp. 312-318, 1991.

[23] M. J. O'Donnell, D. Xavier, L. Liu et al., "Risk factors for ischaemic and intracerebral haemorrhagic stroke in 22 countries (the INTERSTROKE study): a case-control study," Lancet, vol. 376, no. 9735, pp. 112-123, 2010.

[24] P. Parmar, R. Krishnamurthi, M. A. Ikram et al., "The Stroke Riskometer $^{\mathrm{TM}}$ app: validation of a data collection tool and stroke risk predictor," International Journal of Stroke, vol. 10, no. 2, pp. 231-244, 2015.

[25] F. Cosentino, P. J. Grant, V. Aboyans et al., "2019 ESC Guidelines on diabetes, pre-diabetes, and cardiovascular diseases developed in collaboration with the EASD," European Heart Journal, vol. 41, no. 2, pp. 255-323, 2020.

[26] S. Bangalore, G. Kamalakkannan, S. Parkar, and F. H. Messerli, "Fixed-dose combinations improve medication compliance: a meta-analysis," American Journal of Medicine, vol. 120, no. 8, pp. 713-719, 2007.

[27] Stroke Riskometer ${ }^{\mathrm{TM}}$ March 2020, https://www.strokeriskometer .com/.

[28] G. Mancia, R. Fagard, K. Narkiewicz et al., "2013 practice guidelines for the management of arterial hypertension of the European Society of Hypertension (ESH) and the European
Society of Cardiology (ESC)," Journal of Hypertension, vol. 31, no. 10, pp. 1925-1938, 2013.

[29] V. L. Burt, P. Whelton, E. J. Roccella et al., "Prevalence of hypertension in the US adult population," Hypertension, vol. 25, no. 3, pp. 305-313, 1995.

[30] E. Falaschetti, J. Mindell, C. Knott, and N. Poulter, "Hypertension management in England: a serial cross-sectional study from 1994 to 2011," Lancet, vol. 383, no. 9932, pp. 1912-1919, 2014.

[31] B. Boden-Albala and R. L. Sacco, "Lifestyle factors and stroke risk: exercise, alcohol, diet, obesity, smoking, drug use, and stress," Current Atherosclerosis Report, vol. 2, no. 2, pp. 160 166,2000

[32] A. Gentil, Y. Bejot, L. Lorgis et al., "Comparative epidemiology of stroke and acute myocardial infarction: the Dijon Vascular project (Diva)," Journal of Neurology Neurosurgery Psychiatry, vol. 80, no. 9, pp. 1006-1011, 2009.

[33] M. Niewada and P. Michel, "Lifestyle modification for stroke prevention," Current Opinion in Neurology, vol. 29, no. 1, pp. 9-13, 2016.

[34] P. Bramlage, M. Böhm, M. Volpe et al., “A global perspective on blood pressure treatment and control in a referred cohort of hypertensive patients," Journal Clinical Hypertension, vol. 12, no. 9, pp. 666-677, 2010.

[35] M. H. Strauss and A. S. Hall, "Angiotensin receptor blockers may increase risk of myocardial infarction," Circulation, vol. 114 , no. 8, pp. 838-854, 2006, Retraction in: Circulation. 2006 Nov 7;114(19):e576.

[36] N. ISo, "KDIGO clinical practice guideline for the management of blood pressure in chronic kidney disease," Official Journal of the International Society of Nephrology KDIGO, vol. 2, 2012.

[37] R. Kreutz, J. Scholze, and A. Douros, "Single-pill triple fixed dose combination therapy with single component drug monitoring in treatment-resistant hypertension: a pilot study," Current Vascular Pharmacology, vol. 16, no. 2, pp. 197-203, 2018.

[38] S. V. Nedogoda and V. J. Stojanov, "Single-pill combination of perindopril/indapamide/amlodipine in patients with uncontrolled hypertension: a randomized controlled trial," Cardiology and therapy, vol. 6, no. 1, pp. 91-104, 2017.

[39] B. Dahlöf, P. S. Sever, N. R. Poulter et al., "Prevention of cardiovascular events with an antihypertensive regimen of amlodipine adding perindopril as required versus atenolol adding bendroflumethiazide as required, in the Anglo-Scandinavian Cardiac Outcomes Trial-Blood Pressure Lowering Arm (ASCOT-BPLA): a multicentre randomised controlled trial," Lancet, vol. 366, no. 9489, pp. 895-906, 2005.

[40] A. Patel, "Effects of a fixed combination of perindopril and indapamide on macrovascular and microvascular outcomes in patients with type 2 diabetes mellitus (the ADVANCE trial): a randomised controlled trial," The Lancet, vol. 370, no. 9590, pp. 829-840, 2007. 